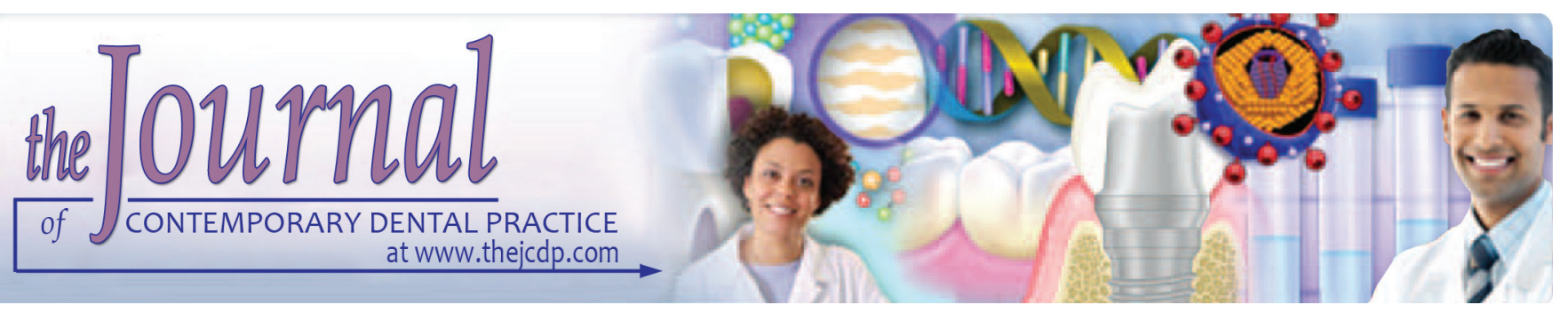

\title{
An In Vitro Evaluation of Antimicrobial Effects of Three Different Root Canal Irrigating Solutions against Enterococcus faecalis and Streptococcus mutans
}

${ }^{1}$ Prashant Bhasin, ${ }^{2}$ Mohit Sharma, ${ }^{3}$ Deepti Bindal, ${ }^{4}$ Deepak Tomar, ${ }^{5}$ Anurag Sarin, ${ }^{6}$ Naren Sharma

\begin{abstract}
Aim: The present study was conducted to evaluate and compare antimicrobial effect of $5.25 \%$ sodium hypochlorite ( $\mathrm{NaOCl}$ ), 2\% chlorhexidine (CHX) and $\mathrm{N}$-Acetylcysteine (NAC) irrigating solutions against Enterococcus faecalis (E. faecalis) and Streptococcus mutans (S. mutans).

Materials and methods: The present study was conducted on 40 freshly extracted noncarious permanent mandibular incisors teeth of both genders (males-12, females-14). In all teeth, root canal preparation was done up to size $40 \mathrm{~K}$-file. Roots were sterilized and microbial suspension of mixed culture of the tested microorganisms was inoculated into canals and incubated for $48 \mathrm{~h}$. Teeth were divided into four groups, group I ( $5.25 \%$ sodium hypochlorite), group II ( $2 \%$ chlorhexidine), group III (200 mg/mL N-Acetylcysteine NAC) and group IV (sterile distilled water). The antimicrobial effect in each group was compared.
\end{abstract}

Results: Statistical evaluation was completed using statistical software Statistical Package for the Social Sciences (SPSS). Planktonic S. mutans bacterial count was lowest in group III followed by group I, group II and group IV. E. faecalis count was $6.14 \pm 0.12$ in group I, $5.76 \pm 0.44$ in group II, $3.88 \pm 0.08$ in group III and $11.98 \pm 1.04$ in group IV. The difference was significant $(p<0.05)$. The proportion of dead cell found to be $0.04 \pm 0.01$, $0.72 \pm 0.06,0.01 \pm 0.06$ and $1.02 \pm 0.11$ in groups I, II, III and IV respectively. The difference was significant $(p<0.05)$.

Conclusion: NAC proved to be effective against $E$. faecalis and $S$. mutans. This solution can be considered alternative in root canal infections in addition with $\mathrm{CHX}$ and $\mathrm{NaOCl}$.

Clinical significance: Effectiveness of three different irrigating solutions was compared and NAC found to be more efficient in

\footnotetext{
1-6Department of Conservative Dentistry and Endodontics, Shree Bankey Bihari Dental College and Research Centre, Ghaziabad, Uttar Pradesh, India
}

Corresponding Author: Mohit Sharma, Department of Conservative Dentistry and Endodontics, Shree Bankey Bihari Dental College and Research Centre, Ghaziabad, Uttar Pradesh, India, Phone: +919953523848, e-mail: sharmamohitdr@gmail.com decreasing bacterial count. Hence, NAC can be precisely used in irrigating root canals to achieve optimal clinical outcomes particularly regarding reoccurrences of infections. Furthermore, NAC could be proved as a promising innovation in future endodontic methodologies.

Keywords: Chlorhexidine, Confocal laser scanning microscopy, Irrigating solution, Streptococcus mutans.

How to cite this article: Bhasin P, Sharma M, Bindal D, Tomar D, Sarin A, Sharma N. An In Vitro Evaluation of Antimicrobial Effects of Three Different Root Canal Irrigating Solutions against Enterococcus faecalis and Streptococcus mutans. J Contemp Dent Pract 2019;20(2):221-225.

Source of support: Nil

Conflict of interest: None

\section{INTRODUCTION}

Endodontic treatment (ET) or root canal treatment (RCT) is a common treatment modality in endodontics. The basic ideology and principle is the complete eradication of root canal irritants, cleaning, and shaping, obturation of root canals and post-endodontic restoration. It majorly involves access opening, cleaning the canals using various instruments along with the use of irrigating solution for instance sodium hypochlorite. Subsequently, the obturation of prepared canals is completed using obturating materials like gutta-percha. After completion of root canal treatment, the tooth is restored with various permanent restorative materials like amalgam, composite or GIC depending upon clinical condition. ${ }^{1}$ As a proven fact, root canal treatment (RCT) significantly reduces the severity of pain. However, the persistence of pain in RC treated teeth could be possibly due to the penetration of pulpal tissues, dentinal debris, microorganisms and irrigants to the periapical tissues leading to periradicular infection and inflammation. The successful endodontic treatment largely depends on the absolute removal of 
microorganisms from the root canals and prevention of reinfection. ${ }^{2}$ Some of the prominent bacterium, such as $E$. faecalis and $S$. mutans play an imperative role in persistence root canal infection. These bacteria frequently lead to root canal treatment failure solely because of their incomplete eradication. It has also been observed that several other traits of E. faecalis are persistently present in root canals. ${ }^{3}$ This is mainly because of their invasion into dentinal tubules and frequent adaptation to adverse conditions. Therefore the role of root canal irrigating solutions is of paramount importance undoubtedly. Sodium hypochlorite ( $\mathrm{NaOCl})$, chlorhexidine (CHX) and NAC (N-Acetylcysteine) are some of the prominent irrigating solutions those are widely used in the field of endodontics. ${ }^{4}$ This study was conducted to evaluate and compare the antimicrobial effect of sodium hypochlorite ( $\mathrm{NaOCl}), 2 \%$ chlorhexidine (CHX) and NAC irrigating solutions against $E$. faecalis and S. mutans. The presence of dead bacterial cells in the biofilm was also assessed by confocal laser scanning microscopy (CLSM). Here authors had genuinely attempted to explore the existing outcomes by processing the observations and other relevant findings.

\section{MATERIALS AND METHODS}

This study was conducted in the Department of Conservative Dentistry and Endodontics of the Institute. The studied samples were 40 freshly extracted noncarious permanent mandibular incisors teeth of both genders. All 40 samples were belonging to 12 male and 14 female subjects. Primarily, teeth extracted because of orthodontic or periodontal reasons were selected for the study. The study was being presented and approved by the institutional ethical committee. Initially, all sample teeth were sectioned through cervical region using with a diamond disc with air rotor headpiece. Measurements of working length for each root were completed radiographically with $10 \mathrm{~K}$ sized file. Using step back technique, thorough preparation of root canals were done up to $40 \mathrm{~K}$ sized file. In the beginning, the root canal irrigation was done with plain distilled water. Soon after preparation of root canal, the apical foramen was sealed with self-curing acrylic resins (DPI Self Cure, Bombay Burmah Trading Corporation, Limited, Mumbai, India). Roots were completely sterilized, and inoculation of microbial suspension of mixed culture of the tested microorganisms was done into canals. The complete sets of tested samples were incubated for 48 hours. For the ease of study and analysis, the sample teeth were arbitrarily divided into four groups of 10 each based on irrigating solutions used. Group I samples were subjected to $5.25 \%$ sodium hypochlorite (NaOCl), group II samples were subjected to $2 \%$ chlorhexidine (CHX), group III samples were subjected to $200 \mathrm{mg} / \mathrm{mL}$ N-Acetylcysteine (NAC) solution, and group IV samples were subjected sterile distilled water.

First and foremost, bacteriological samples were obtained from root canal milieu. In these bacteriological samples, the total number of colony forming units (cfu) of the tested bacterium was calculated. After that, each root was cut down in a lengthwise manner to expose the pulp canal (Fig. 1). A standard length of $4 \mathrm{~mm}$ was cut and obtained from the middle portion of either side sectioned root piece. To avoid any superimposition and overlapping of bacterial colonies, the sectioned pieces were completely sterilized. The premixed and prepared microbial suspensions were used to inoculate these sectioned pieces for minimum 48 hours. The quantity of irrigation solution used in each group was $5 \mathrm{~mL}$ with an immersion time of 5 minutes. The relative presences of dead bacterial cells in the formed biofilm were also identified and studied by ( LSM) at 10X magnification in the fluorescent mode. Results thus obtained were subjected to statistical analysis wherein $p$ value less than 0.05 was considered significant.

\section{RESULTS}

All the observational findings were compiled and sent for statistical evaluation using statistical software SPSS version 21 (IBM Inc., Armonk, New York, USA). The resultant data was subjected to relevant statistical tests to obtain $p$ values and other inferences. The irrigating solution used was $5.25 \%$ sodium hypochlorite $(\mathrm{NaOCl}), 2 \%$ chlorhexidine (CHX), $200 \mathrm{mg} / \mathrm{mL} \mathrm{N}$-Acetylcysteine (NAC) and Sterile distilled water in group I, II, III and IV respectively (Table 1). There were 10 teeth in each group. Planktonic $S$. mutans bacterial count was highest in group IV and lowest in group III. Precisely, it was $3.84 \pm 0.28$ in group I, 4.82 \pm 0.86 in group II, $3.12 \pm 0.76$ in group III and $12.91 \pm 2.14$ in group IV. E. faecalis count was found the maximum in group IV and minimum in group III. Quantitatively

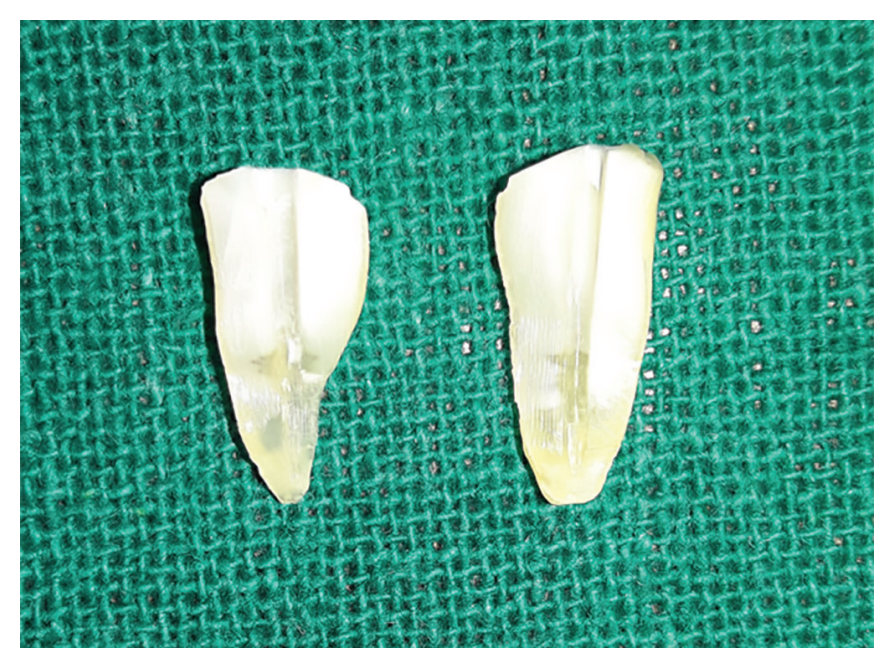

Fig. 1: Sample teeth showing exposed root canal lumen 
Irrigating Solutions against Enterococcus faecalis and Streptococcus mutans

Table 1: Types of irrigating solutions used in study

\begin{tabular}{|c|c|c|c|c|}
\hline Groups & Group I & Group II & Group III & Group IV \\
\hline Solutions & $\begin{array}{l}5.25 \% \text { Sodium } \\
\text { hypochlorite }(\mathrm{NaOCl})\end{array}$ & $2 \%$ Chlorhexidine (CHX) & $\begin{array}{l}200 \mathrm{mg} / \mathrm{mL} \text { N-Acetylcysteine } \\
\text { (NAC) }\end{array}$ & Sterile distilled water \\
\hline No. of teeth & 10 & 10 & 10 & 10 \\
\hline
\end{tabular}

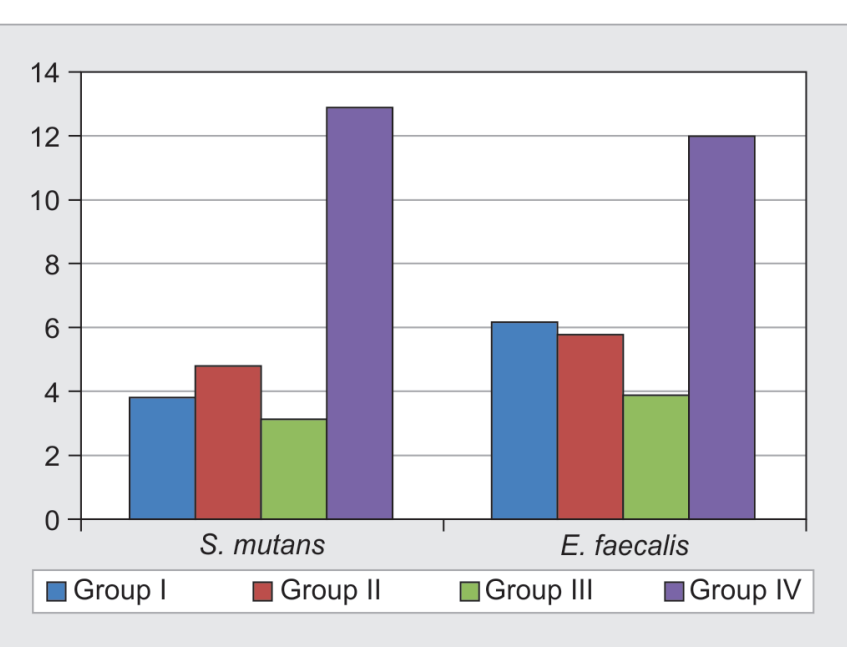

Graph 1: Graphical representation of planktonic bacterial count in each group

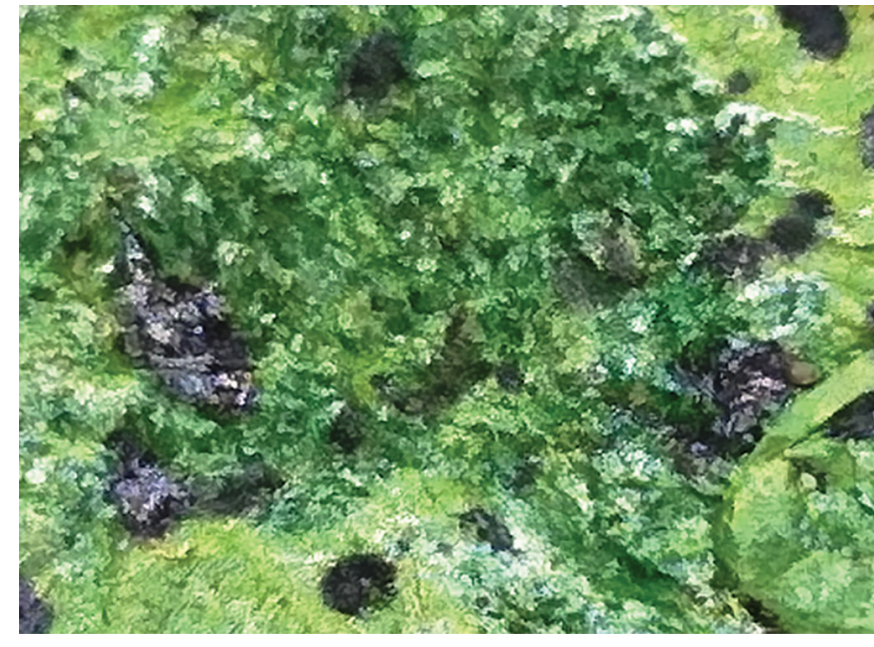

Fig. 2: Confocal laser scanning microscopic image confirming higher proportions of dead cells (10X magnification in the fluorescent mode) in group IV specimen

Table 2: Planktonic bacterial count in each group

\begin{tabular}{llllll}
\hline $\begin{array}{l}\text { Planktonic } \\
\text { bacterial }\end{array}$ & Group I & Group II & Group III & Group IV & p value \\
\hline S. Mutans & $3.84 \pm 0.28$ & $4.82 \pm 0.86$ & $3.12 \pm 0.76$ & $12.91 \pm 2.14$ & 0.01 \\
E. Faecalis & $6.14 \pm 0.12$ & $5.76 \pm 0.44$ & $3.88 \pm 0.08$ & $11.98 \pm 1.04$ & 0.02 \\
\hline$p<0.05$ significant & & & & &
\end{tabular}

$p<0.05$ significant

it was $6.14 \pm 0.12$ in group I, $5.76 \pm 0.44$ in group II, $3.88 \pm 0.08$ in group III and $11.98 \pm 1.04$ in group IV (Graph I and Table 2). The difference was significant $(p<0.05)$. CLSM was used to identify and proportionate the relative presences of dead bacterial cells in the formed biofilm. The CLSM evaluation revealed that the relative presence of a bacterial proportion of dead cell in biofilm was maximum in group IV (Fig. 2) and minimum in group III (Graph 2 and Table 3). Quantitatively they were $0.04 \pm 0.01$ in group $I, 0.72$ \pm 0.06 in group II, $0.01 \pm 0.06$ in group III and $1.02 \pm 0.11$ in group IV. The difference was significant $(p<0.05)$. The overall results indicated that NAC had maximum antibacterial activity as compared with other irrigating solutions including sterile distilled water.

\section{DISCUSSION}

Literature has well evidenced that the overall success of endodontic treatment is healthily appreciated by

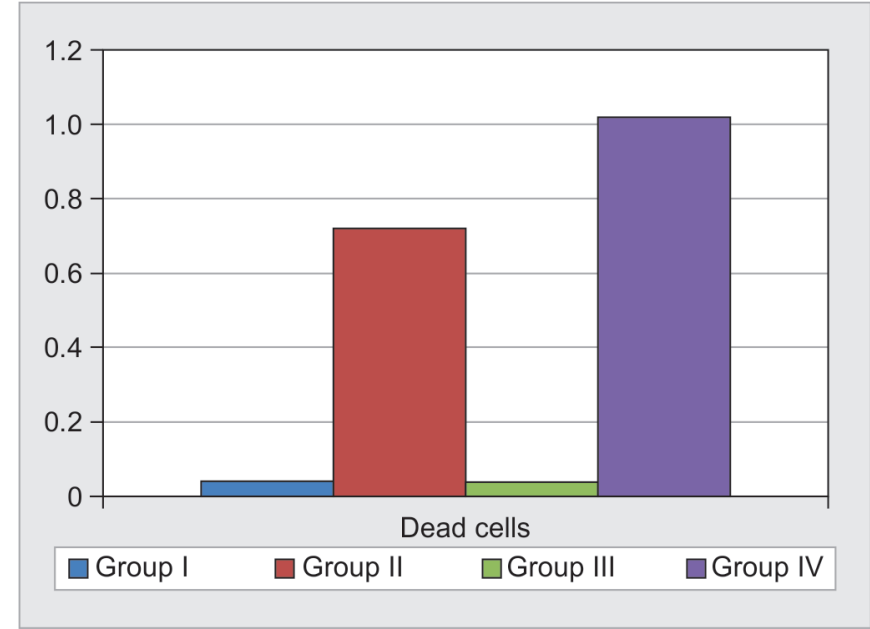

Graph 2: Graphical representation of proportions of dead cells in each group

patients. There are few factors which affect success rates such as inadvertently missed strands of pulp tissue, failure to adequately seal the access cavity and even noncooperation of the patient with respect to postoperative

Table 3: Proportions of dead cells in each group

\begin{tabular}{llllll}
\hline & Group I & Group II & Group III & Group IV & $p$ value \\
\cline { 2 - 6 } Proportion of dead cell & $0.04 \pm 0.01$ & $0.72 \pm 0.06$ & $0.01 \pm 0.06$ & $1.02 \pm 0.11$ & 0.01 \\
\hline$p<0.05$ significant & & & & &
\end{tabular}


instructions. Moreover, any potent insult or injury to the periapical tissue during endodontic treatment results into more rigorous secretion of inflammatory mediators. These inflammatory mediators are also considered as mediators of pain for example prostaglandins, serotonin, leukotrienes, histamine, and bradykinin. ${ }^{5}$ It was postulated that bacteria in the root canals forms biofilm by attaching to root canal walls or may occur as single cells as freefloating or attached. Most commonly encountered bacteria in root canals are E. faecalis and S. mutans. E. faecalis is a versatile pathogenic bacterium which is one of the leading causes of endodontic failures in most of the cases. ${ }^{6}$ Stuart et al suggested that the prevalence of E. faecalis ranges from 24 to $77 \%{ }^{7}$ It is a gram-positive facultative anaerobic cocci may occur singly or in a pair. It has the property of invading into dentinal tubules and competes with other microorganisms. Kishen et al. conducted an in vitro study and suggested that E. faecalis initiates biofilm formation on root canal dentine which calcifies over the years and becomes a full-fledged calcified layer. ${ }^{8}$ Silva et al. found the invasion of E. faecalis in dentinal tubules. The author observed that bacteria itself may be the infectious agent in root canals. S. mutans is a gram-positive aerobic bacterium which shows its presence in root canals of teeth. It has been observed that $S$. mutans species in root canals contribute to microbe-microbe interactions which ultimately enhance total biofilm formation. Combination of $S$. mutans and E. faecalis forms a strong biofilm. ${ }^{9}$ This interaction poses difficulty for antimicrobials agents to show effect. Different species of Streptococcus has been isolated in multiple situations. Chavez observed Streptococcus species in $47 \%$ of retreatment cases. ${ }^{10}$ Some of the other pioneer studies have also shown the presence of bacteria during intracanal dressings, before and after instrumentation. ${ }^{11,12}$

In the present study, we used $5.25 \%$ sodium hypochlorite ( $\mathrm{NaOCl}), 2 \%$ chlorhexidine (CHX), $200 \mathrm{mg} /$ $\mathrm{mL} N$-Acetylcysteine (NAC) and sterile distilled water as an irrigating solution. We observed that planktonic bacterial count was significantly higher in group IV in which sterile distilled water was used as compared to groups I-III. This is in agreement with the study by Darrag. ${ }^{13}$ Arias et al. found that $5.25 \%$ sodium hypochlorite is more effective as compared to $2 \%$ chlorhexidine. ${ }^{14} \mathrm{NaOCl}$ has higher antibacterial efficacy and it prevents attachment of bacteria to other bacteria and dentinal walls due to its organic tissue solvent nature. Similarly, in the present study, bacterial count was lower in group I as compared to groups II-IV. We used $2 \%$ chlorhexidine as it has a bacteriostatic action and bactericidal effect at higher concentrations. Commonly available sterile distilled water is a absolutely nonreactive solution with no antimicrobial effect. $200 \mathrm{mg} / \mathrm{mL}$ of NAC solution was used as at this concentration, the important effect is observed. Berber and colleagues compared different concentrations of $\mathrm{NaOCl}$ in reducing E. faecalis in root canal lumen. ${ }^{15}$ It was seen that disinfection of the dentinal tubules occurs at the higher concentrations. We observed that the proportion of dead cell was higher in group IV as compared to other groups. Cindy et al. in their study revealed that NAC is more efficient in reducing dead cell proportion as compared to $\mathrm{CHX} \cdot{ }^{16} \mathrm{We}$ also observed reduced dead cell proportion with NAC as compared to $\mathrm{NaOCl}$ and $\mathrm{CHX}$. It is shown that both $\mathrm{NaOCl}$ and $\mathrm{CHX}$ are less effective on smear layer due to the buffering capacity of dentin. Therefore our results were in accordance with the study results of Cindy and associates. NAC is usually considered as a strong antioxidant that slowdowns polysaccharide formation and operating on the bacterial cell wall. It prevents the attachment of bacteria on dentinal walls by inhibiting polysaccharide formation, the potent component of biofilm. Thus it shows its effect indirectly. It was observed that all solutions were effective in reducing $S$. mutans concentration as compared to $E$. faecalis. CHX is both bactericidal and bacteriostatic that primarily acting on bacterial cell wall's phospholipids. Hugo et al. showed that it shows the effect by inhibiting ATPase enzyme attachment to the bacterial cell wall. ${ }^{17}$ The production of ATP is hindered, and hence bacterial growth ceases. Vianna et al. analyzed the antimicrobial efficacy of $0.2 \%, 1 \%$, and $2 \%$ chlorhexidine gluconate in gel and liquid form with $0.5 \%, 1 \%, 2.5 \%, 4 \%$, and $5.25 \%$ sodium hypochlorite $(\mathrm{NaOCl}){ }^{18}$ They noticed that S. aureus and Candida albicans totally vanished in 15 seconds with both $2.0 \%$ gel and liquid suspensions while the gel suspensions killed E. faecalis in 1 minute. The timing required for $1.0 \%$ and $2.0 \% \mathrm{CHX}$ liquid to eliminate all microorganisms was the same required for $5.25 \%$ $\mathrm{NaOCl}$. Their study results were quite comparable to our inferences. Studies conducted by Anuradha et al. and Yap et al. have also shown similar comparisons. ${ }^{19,20}$ However, they have not emphasized on the clinical applicability of the irrigants in different clinical situations. In a recent study by Palaniswamy and colleagues, they evaluated the antibacterial efficacies of chlorhexidine and NAC wherein they concluded that NAC has almost equal antimicrobial property as chlorhexidine. ${ }^{21}$ Their results were quite contrasting when compared to our inferences. It could be explained on the basis of differences in the methodology particularly in terms of Agar diffusion test and incubation timings. Ghivari et al. also evaluated three irrigants wherein they found that Sodium hypochlorite irrigants have shown lowered antibacterial activity against selected single species biofilm. ${ }^{22}$ They used nitrocellulose biofilm model to estimate antibacterial efficiency of tested root canal irrigants. Their study results were comparable to our inferences. In the present study, though the authors have tried to cover maximum aspects still there are some 
viable limitation like authors only studied two species of bacteria, i.e., E. faecalis and S. mutans. Moreover, apart from the other available advanced irrigating materials, only four solutions such as sodium hypochlorite, chlorhexidine, sterile distilled water, and NAC were compared. A root canal may be infected with a variety of microorganisms; hence study on multiple bacteria could have been proved fruitful.

\section{CONCLUSION}

$N$-Acetylcysteine proved to be effective against $E$. faecalis and $S$. mutans. It showed good antibacterial and biofilm eradication efficiencies. Hence, NAC solution can be considered as a potent alternative for root canal disinfection in addition with $\mathrm{CHX}$ and $\mathrm{NaOCl}$. Furthermore, the maximum proportion of dead cell was seen in samples treated with sterile distilled water. Here, NAC was shown to be most effective in eradicating biofilm when compared to other tested irrigating solutions ( $\mathrm{CHX}$ and $\mathrm{NaOCl}$ ). Our study results can be considered as suggestive for predicting clinical outcomes for such clinical situations. Nevertheless, we expect other large scale studies to be conducted that could further establish certain concrete guidelines in this prospect.

\section{CLINICAL SIGNIFICANCE}

NAC is completely systemically nontoxic and has a broad antimicrobial spectrum hence highly effective against aerobic, anaerobic and other discretionary microorganisms. Therefore, NAC can be efficiently used in irrigating root canals to achieve optimal clinical outcomes particularly regarding reoccurrences of infections. Furthermore, NAC could be possibly providing some newer avenues in root canal irrigation systems in future endodontic methodologies.

\section{REFERENCES}

1. Haapasalo M, Shen Y, Qian W, Gao Y. Irrigation in endodontics. Dent Clin North Am 2010;54:291-312.

2. Mohammadi Z, Abbott PV. The properties and applications of chlorhexidine in endodontic: review. Int Endod J 2009;42: 288-302.

3. Rucucci D, Siqueira JF. Biofilms and apical periodontitis: study of prevalence and association with clinical and histopathologic findings. J Endod 2010;36:1277-1288.

4. Ferraz CC, Gomes BP, Zaia AA, Teixeira FB, Souza E, Filho FJ. In vitro assessment of the antimicrobial action and the mechanical ability of chlorhexidine gel as an endodontic irrigant. J Endod 2001;27:452-455.

5. Charles H. Stuart, Scott A. Schwartz, Thomas J. Beeson, Christopher B. Owatz. Enterococcus faecalis: It's Role in Root
Canal Treatment Failure and Current Concepts in Retreatment. JOE 2006;32:93-98.

6. Koch S, Hufnagel M, Theilacker C, Huebner J. Enterococcal infections: host response, therapeutic, and prophylactic possibilities. Vaccine 2004;22:822-830.

7. Stuart CH, Schwartz SA, Beeson TJ, Owatz CB. Enterococcus faecalis: its role in root canal treatment failure and current concepts in retreatment. J Endod 2006;32:93-98.

8. Kishen A, George S, Kumar R. Enterococcus faecalis-mediated biomineralized biofilm formation on root canal dentine in vitro. J Biomed Mater Res 2006;77:406-415.

9. da Silva LA, Nelson-Filho P, Faria G, de Souza-Gugelmin MC. Bacterial profile in primary teeth with necrotic pulp and periapical lesions. Braz Dent J 2006;17:144-148.

10. Chavez de Paz L. Gram-positive organisms in endodontic infections. Endod Top 2004;9:79-96.

11. Vijaykumar S, Guna Shekhar M, Himagiri S. In vitro effectiveness of different endodontic irrigants on the reduction of Enterococcus faecalis in root canals. J Clin Exp Dent 2010;2:169172.

12. Estrela C, Silva JA, Goncalves De, Alencar AH, Leles CR, Decurcio DA. Efficacy of sodium hypochlorite and chlorhexidine against Enterococcus faecalise-a systematic review. J Appl Oral Sci 2008;16:364-368.

13. Darrag AM. Antimicrobial efficacy of endodontic irrigation solutions against planktonic microorganisms and dualspecies biofilm. Tanta Den J 2013;129-137.

14. Arias-Moliz MT, Ferrer-Luque CM, Espigares-Garcýa M, Baca P. Enterococcus faecalis biofilms eradication by root canal irrigants. J Endod 2009;35:711-714.

15. Berber VB, Gomes BP, Sena NT, Vianna ME, Ferraz CC, Zaia AA, et al. Efficacy of various concentrations of $\mathrm{NaOCl}$ and instrumentation techniques in reducing Enterococcus faecalis within root canals and dentinal tubules. Int Endod J 2006;39:10-17.

16. Cindy HR, Rene HD, Sergio GR, Diana RP, Claudio CR. Rifampicin and $\mathrm{N}$-acteylcisteyne inhibit oral bacterial growthand biofilm formation. Pharmaceut Innovat J 2013;2:16-23.

17. Hugo WB, Russell AD. Chemical disinfectants, antiseptics, and preservatives. In: Pharmaceutical microbiology. 6th ed. Blackwell Science Ltd; 2000.

18. Vianna ME, Gomes BP, Berber VB, Zaia AA, Ferraz CC, Jose' de Souza-Filho F. In vitro evaluation of the antimicrobial activity of chlorhexidine and sodium hypochlorite. Oral Surg Oral Med Ora Pathol Oral Radiol Endod 2004;97:79-84.

19. Anuradha B, Rajamoni I, Lalitha MK, Sriram T. A new irrigant against E.faecalis in the root canal disinfection. Biosci Biotech Res Asia 2014;11:121-127.

20. Yap B, Zilm PS, Briggs N, Rogers AH, Cathro PC. The effect of sodium hypochlorite on Enterococcus faecalis when grown on dentine as a single- and multi-species biofilm. Aust Endod J 2014;40:101-110.

21. Palaniswamy U, Lakkam SR, Arya S, Aravelli S. Effectiveness of $\mathrm{N}$-acetyl cysteine, $2 \%$ chlorhexidine, and their combination as intracanal medicaments on Enterococcus faecalis biofilm. J Conserv Dent 2016;19:17-20.

22. Ghivari SB, Bhattacharya H, Bhat KG, Pujar MA. Antimicrobial activity of root canal irrigants against biofilm forming pathogens-An in vitro study. J Conserv Dent 2017;20:147-151. 